\title{
Characterization of Radiation Fields for Assessing Concrete Degradation in Biological Shields of NPPs
}

\author{
Igor Remec ${ }^{1, *}$, Thomas M. Rosseel ${ }^{1}$, Kevin G. Field ${ }^{1}$ and Yann Le Pape ${ }^{1}$ \\ ${ }^{1}$ Oak Ridge National Laboratory, P.O. Box 2008, Oak Ridge, TN 37831-6170, USA
}

\begin{abstract}
Life extensions of nuclear power plants (NPPs) to 60 years of operation and the possibility of subsequent license renewal to 80 years have renewed interest in long-term material degradation in NPPs. Large irreplaceable sections of most nuclear generating stations are constructed from concrete, including safety-related structures such as biological shields and containment buildings; therefore, concrete degradation is being considered with particular focus on radiation-induced effects. Based on the projected neutron fluence values $(\mathrm{E}>0.1 \mathrm{MeV})$ in the concrete biological shields of the US pressurized water reactor fleet and the currently available data on radiation effects on concrete, some decrease in mechanical properties of concrete cannot be ruled out during extended operation beyond 60 years. An expansion of the irradiated concrete database is desirable to ensure reliable risk assessment for extended operation of nuclear power plants.
\end{abstract}

\section{Introduction}

Numerous nuclear power plants (NPPs) in the USA have received approval to extend their licenses to operate up to 60 years and further extensions, to 80 years and beyond, are being considered to meet future national energy needs while reducing greenhouse gas emissions. NPPs lifetime extensions have renewed interest in long-term aging of materials in general and recently in concrete. Large structures of NPPs are built from concrete, including safety-related structures such as the biological shields and containment buildings. Concrete is a complex material and its properties change over time due to slow hydration, crystallization of amorphous components, reactions between cement paste and aggregates, and the effects of the local environment such as humidity, temperature, and for NPP concrete, radiation exposure.

Most of the legacy data on mechanical performance of irradiated concrete were analyzed by Hilsdorf et al. [1], (1978) who concluded that, for some concretes, neutron fluence of $1.0 \times 10^{19} \mathrm{n} / \mathrm{cm}^{2}$ may cause a reduction in compressive and tensile strength and a marked increase in volume. Although it was implied that the effects depend on the neutron fluence being "fast" or "thermal," the report did not quantify the differences and did not address the effect of the gamma rays. In addition, a recent review of Hillsdorf's data by Kontani et al.[2] (2013) revealed that most data points at high end of neutron fluence range were obtained at irradiation temperatures above $100^{\circ} \mathrm{C}$ and were using either aluminous cement or liquid glass aggregate, which is not representative of the environment and materials used in concrete for NPPs. Therefore it is not surprising that the recently completed Expanded
Materials Degradation Analysis, jointly performed by the Department of Energy, the Nuclear Regulatory Commission and Nuclear Industry, identified the urgent need to develop a consistent knowledge base on irradiation effects in concrete [3]. A research program on concrete aging and degradation processes in NPPs was established within the Light Water Reactor Sustainability (LWRS) program under the US Department of Energy (DOE) and is being performed in partnership with the Electric Power Research Institute's Long-Term Operations (LTO) Program. This paper outlines recent progress in the irradiated concrete research program with a focus on the assessment of the radiation environment in concrete biological shields in NPPs.

\section{Radiation Environments in Concrete Biological Shields}

The radiation-induced concrete degradation has been historically correlated to neutron fluence; therefore, it is necessary to estimate the bounding fluence values for the US NPP fleet at the projected extended service. Due to the substantial differences in reactor designs and variations in plant operations, this effort is not trivial. There is no routine monitoring of radiation fields in biological shields of NPPs. However, every operating US NPP is required to conduct a reactor pressure vessel (RPV) surveillance program and a wealth of RPV fluence information is publicly available from the US NRC ADAMS database [4]. The RPV flux/fluence data need to be extrapolated in concrete biological shield (CBS). For this purpose coupled neutron and gamma ray transport

\footnotetext{
* Corresponding author: remeci@ornl.gov
} 
calculations were performed for a three-loop and a twoloop pressurized water reactor (PWR), utilizing the slightly modified computer models previously generated for the RPV fluence investigations [5]. An example of the attenuation of the neutron and gamma flux through the pressure vessel and CBS is shown in Figure 1.

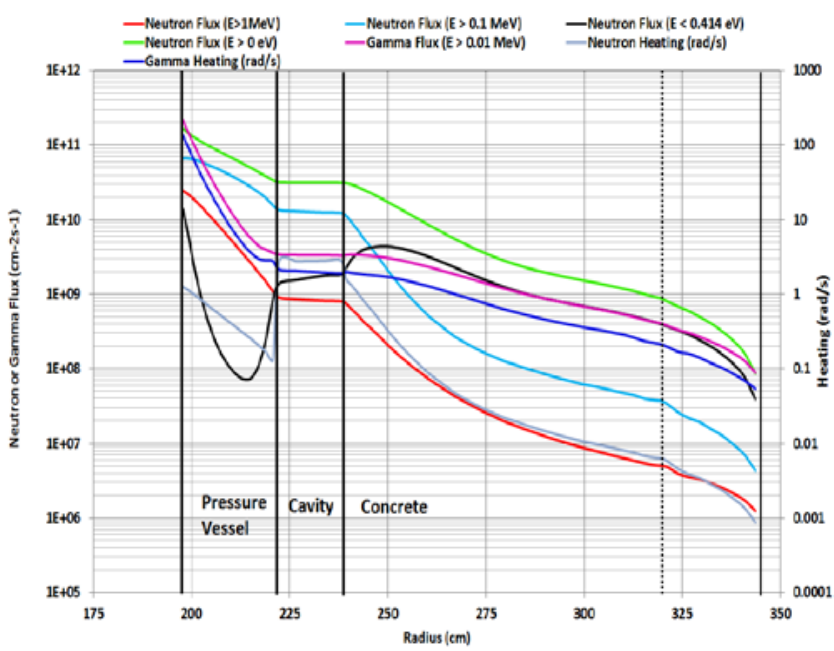

Figure 1. Radial variation of neutron flux at four energy ranges, gamma-ray flux, and heating rates for a three-loop pressurized water reactor.

With the data retrieved from ADAMS, and using the guidance obtained from transport calculations, Esselman and co-workers [6] estimated the neutron fluence values in the CBS, at 80 years of operation, for the current US NPP fleet. The results for the PWRs, which have higher expected neutron fluence values than the boiling water reactors, are shown in Fig. 2. The importance of the plant design is clearly observed: the four loop PWR reactors show significantly lower fluence values than the majority of both 2 and 3 loop plants.

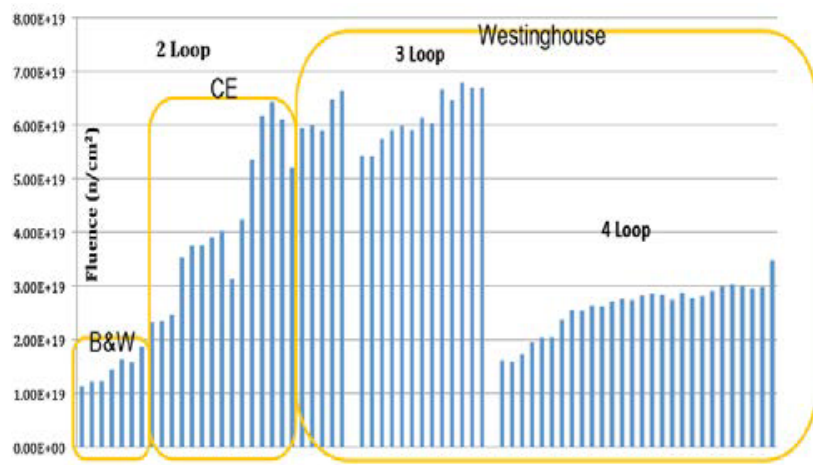

Figure 2. Summary of US PWR fleet neutron fluence $(\mathrm{E}>0.1$ $\mathrm{MeV}$ ) at the biological shield extrapolated to 80 years and grouped by design and manufacturer [6].

\section{Current irradiated concrete database}

While a comprehensive review of the currently available results of irradiated concrete properties is presented in [7], a brief review of the parameter(s) used to characterize the field in which the concrete and its component samples were irradiated will be presented here.
Fig. 3 depicts the ratio of the compressive strength of irradiated concrete to compressive strength of unirradiated concrete versus neutron fluence. The data were taken from [7] and re-processed so that the symbols indicate the energy threshold of the neutron fluence depicted on the abscissa rather than the aggregate type. One notable feature in Fig. 3 is the large variation in residual compressive strength at any given neutron fluence value. The scattering of data, which are assembled from a large number of independent experiments, is caused by variations in numerous factors, such as different types of cement and aggregate, different cement-to-water ratios, different specimen sizes, variation in concrete curing and thermal treatment, and different temperatures of specimens during irradiation.

Of particular interest here is that the reported "neutron fluence" varies greatly between experiments. Some experiments gave only qualitative descriptions such as "slow" or "fast" neutron fluence, some used fluence of neutrons at energies above $0.1 \mathrm{MeV}$, and some above 1.0 $\mathrm{MeV}$, some reported total $(\mathrm{E}>0 \mathrm{MeV})$ fluence, and some experiments did not address the energy of neutrons at all. Moreover, the neutron spectrum was actually provided only for a few experiments. Due to the potentially large variations in neutron spectrum between experiments and even between different locations in the same irradiation, it is not possible to "re-normalize" the database to a common denominator, such as fluence of neutrons with energies $\mathrm{E}>0.1 \mathrm{MeV}$. (This will be referred to as fluence with cutoff of $0.1 \mathrm{MeV}$.)

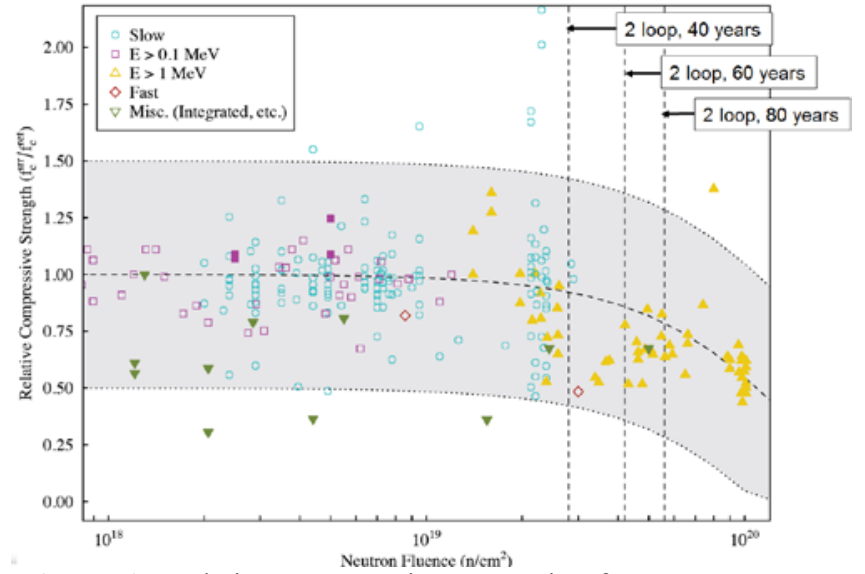

Figure 3. Relative compressive strength of concrete versus neutron fluence. The shapes of the symbols indicate neutron fluence energy cutoff. Solid symbols indicate specimen temperature during irradiation was above $100^{\circ} \mathrm{C}$; hollow symbols correspond to temperature below $100^{\circ} \mathrm{C}$. The fluence $(\mathrm{E}>0.1 \mathrm{MeV}$ ) values for the two-loop PWR (from Table 1), are shown as dashed vertical lines.

Despite not being able to normalize the data to a unique cutoff energy, the neutron fluence cutoff value is crucial for the assessment of concrete degradation in nuclear power plants (NPPs). The values listed in Table 1 , obtained in a transport analysis of a two-loop and three-loop PWR $[5,8]$, indicate that both plants remain below the $1.0 \times 10^{19} \mathrm{n} / \mathrm{cm}^{2}$ fluence value for the $1 \mathrm{MeV}$ cutoff, and therefore no radiation-induced degradation would be expected even for the 80 years of operation. However, for the $0.1 \mathrm{MeV}$ cutoff, both plants exceed the 
$1.0 \times 10^{19} \mathrm{n} / \mathrm{cm}^{2}$ fluence level during 40 years of operation, and some concrete degradation may be expected. This is even more pronounced if the assessment is based on the integral fluence $(\mathrm{E}>0 \mathrm{MeV})$.

Another observation related to Fig. 3 is that the data points at the high fluence end are dominated by the data reported for the fluence energy cutoff of $1 \mathrm{MeV}$. If the data are reported for the cutoff energy of $0.1 \mathrm{MeV}$, the data would move to significantly higher (approximately an order of magnitude) fluences, resulting in a reduced prediction of radiation degradation in the $1-10 \times 10^{19}$ $\mathrm{n} / \mathrm{cm}^{2}$ fluence range.

Table 1. Predicted neutron fluence for the two PWRs analysed at 40,60 , and 80 years of operation assuming a $92 \%$ capacity factor.

\begin{tabular}{|c|c|c|c|c|}
\hline \multirow{2}{*}{$\begin{array}{c}\text { Years } \\
\text { Ope- } \\
\text { ration }\end{array}$} & \multirow[b]{2}{*}{$\begin{array}{l}\text { PWR } \\
\text { Type }\end{array}$} & \multicolumn{3}{|c|}{ Neutron Fluence $\left(\mathrm{n} / \mathrm{cm}^{2}\right)$} \\
\hline & & $\begin{array}{c}\mathrm{E}>0.0 \\
\mathrm{MeV}\end{array}$ & $\begin{array}{l}\mathrm{E}>0.1 \\
\mathrm{MeV}\end{array}$ & $\begin{array}{c}\mathrm{E}>1.0 \\
\mathrm{MeV}\end{array}$ \\
\hline \multirow{2}{*}{40} & 2-loop & $7.3 \times 10^{19}$ & $2.8 \times 10^{19}$ & $3.2 \times 10^{18}$ \\
\hline & 3-loop & $3.6 \times 10^{19}$ & $1.3 \times 10^{19}$ & $8.7 \times 10^{17}$ \\
\hline \multirow[b]{2}{*}{60} & 2-loop & $1.1 \times 10^{20}$ & $4.2 \times 10^{19}$ & $4.9 \times 10^{18}$ \\
\hline & 3-loop & $5.4 \times 10^{19}$ & $2.0 \times 10^{19}$ & $1.3 \times 10^{18}$ \\
\hline \multirow{2}{*}{80} & 2-loop & $1.5 \times 10^{20}$ & $5.6 \times 10^{19}$ & $6.5 \times 10^{18}$ \\
\hline & 3-loop & $7.2 \times 10^{19}$ & $2.6 \times 10^{19}$ & $1.7 \times 10^{18}$ \\
\hline
\end{tabular}

\section{Atom displacements in aggregates}

The radiation-induced swelling of aggregates, which leads to volumetric expansion of the concrete, is currently considered the dominant cause for loss of mechanical properties of irradiated concrete [7]. For this reason we investigated neutron induced atom displacements in aggregates. The displacement-per-atom (dpa) cross sections were generated with computer code Specomp [9] for several widespread aggregate minerals in concrete: Quartz $\left(\mathrm{SiO}_{2}\right)$, Calcite $\left(\mathrm{CaCO}_{3}\right)$, Anorthite $\left(\mathrm{CaAl}_{2} \mathrm{Si}_{2} \mathrm{O}_{8}\right)$, Microcline ( $\left.\mathrm{KAlSi}_{3} \mathrm{O}_{8}\right)$, and Albite $\left(\mathrm{NaAlSi}_{3} \mathrm{O}_{8}\right)$. Fig. 4 depicts the variation of $d p a$ cross-sections with neutron energy; the shapes are very similar to the well-established $d p a$ cross-section for silicon, which was taken from ASTM E 722 [10] and is shown for comparison.

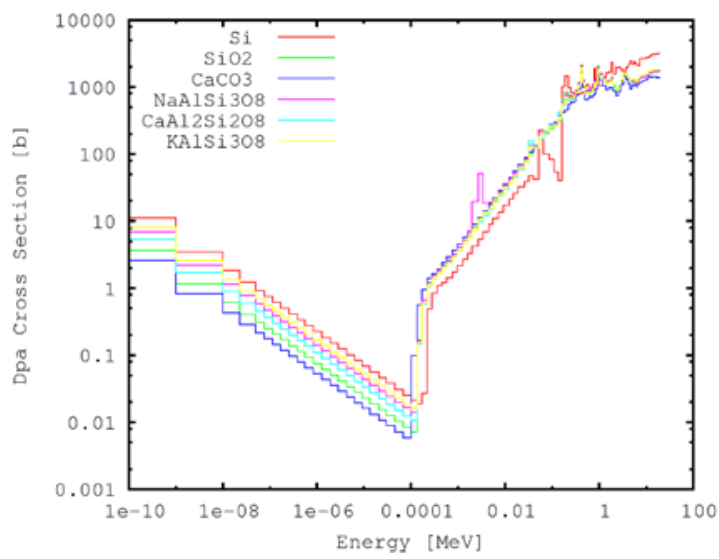

Figure 4. Dpa cross section versus neutron energy for selected minerals commonly used as aggregates in concrete.
These cross sections were folded with the neutron fluence rate spectrum in the cavity of a two-loop PWR and three-loop PWR, obtained from transport calculations, to calculate relative contributions to the $d p a$ rate. The results plotted in Fig. 5 and Fig. 6 show that approximately $90 \%$ of the atom displacements are caused by the neutrons with energies between $0.1 \mathrm{MeV}$ and 2 $\mathrm{MeV}$ while neutrons with energies above $1 \mathrm{MeV}$ cause only about $20 \%$ to $25 \%$ of the total atom displacements. However, neutrons with energies above $0.1 \mathrm{MeV}$ contribute more than $95 \%$ of all atom displacements. These statements hold for all materials considered and for the neutron spectrum in the cavity of a two-loop and three-loop PWR. This clearly indicates that from the perspective of creation of atom displacements in aggregates, neutron fluence with $\mathrm{E}>0.1 \mathrm{MeV}$ is more relevant correlation parameter than the fluence with $\mathrm{E}>$ $1 \mathrm{MeV}$.

The values of the $d p a$ rates for all aggregates considered agree to within $\sim 10 \%$, with the exception of calcite for which the $d p a$ rate is about $20 \%$ smaller.

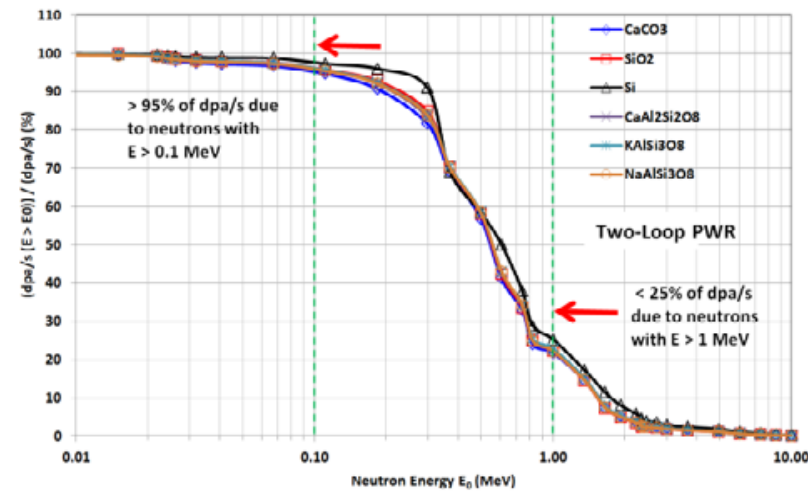

Figure 5. Relative contribution of neutrons with energies $E>E_{0}$ to the $d p a$ rate for the neutron spectrum in the cavity of a twoloop PWR.

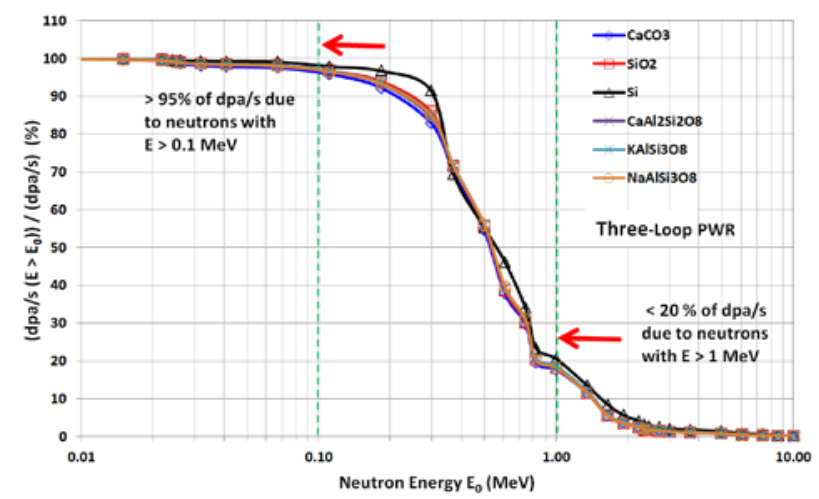

Figure 6. Relative contribution of neutrons with energies $E>E_{0}$ to the $d p a$ rate for the neutron spectrum in the cavity of a threeloop PWR.

\section{Neutron induced absorbed dose in aggregates}

The absorbed dose was often used to assess and correlate the irradiation-induced degradation in particular in insulators [11]. Therefore the analysis described in Section 4 for $d p a$ was repeated for the absorbed dose. 
The results were very similar to those for $d p a$ and will be just briefly summarized. Approximately $85 \%$ of the absorbed dose rate is delivered by the neutrons with energies between $0.1 \mathrm{MeV}$ and $2 \mathrm{MeV}$. The neutrons with energies above $1 \mathrm{MeV}$ deliver $25 \%$ to $35 \%$ of the absorbed dose rate. Neutrons with energies above 0.1 $\mathrm{MeV}$ are responsible for more than $95 \%$ of the absorbed dose rate. These observations hold for all the aggregates considered and for the two-loop and the three-loop PWR plant analyzed. The results therefore indicate that, from the perspective of absorbed dose in aggregates, neutron fluence with $\mathrm{E}>0.1 \mathrm{MeV}$ is more relevant correlation parameter than the fluence with $\mathrm{E}>1 \mathrm{MeV}$.

\section{Conclusions}

In the neutron fluence rate spectra in the cavity of a twoloop and three-loop PWR about $90 \%$ of $d p a$ and absorbed dose in several widespread components of aggregates in concrete: quartz, calcite, albite, anorthite, and microcline, is due to the neutrons in the energy range between 0.1 $\mathrm{MeV}$ and $2 \mathrm{MeV}$. The neutrons with energies above 1 $\mathrm{MeV}$ typically contribute only about $20 \%$ to $35 \%$ to the $d p a$ and absorbed dose. The neutrons with energies above $0.1 \mathrm{MeV}$ typically account for $95 \%$ or more of the $d p a$ and absorbed dose in these materials. These observations, together with the experimental evidence that the radiation induced volumetric expansion of aggregates drives the degradation of concrete mechanical properties, indicate that fluence of neutrons with energy cutoff $0.1 \mathrm{MeV}$ is better correlation parameter than fluence with threshold 1 $\mathrm{MeV}$ and should be used in the future. However, it is also recommended to report full neutron fluence rate energy spectrum and gamma-ray spectrum for all future concrete irradiation experiments.

Available database on irradiated concrete displays large variations in the level of degradation in concrete properties at any neutron fluence value and varying neutron fluence specifications. Besides, the concrete specimens used and the irradiation conditions may not have been representative of the condition in NPPs biological shields, which is particularly true at the fluence levels above $\sim 3.0 \times 10^{19} \mathrm{n} / \mathrm{cm}^{2}$. Additional experiments are therefore needed; some of the undergoing efforts are described in [12].

The performance of concrete structures in the NPPs through the first 40 years of service has been very good and it is expected that the vast majority of these structures will continue to meet their functional and performance requirements during extended licensing periods. However, based on projected neutron fluence values $(\mathrm{E}>$ $0.1 \mathrm{MeV}$ ) in the concrete biological shields of the US PWR fleet and currently available irradiated concrete database, some decrease in the mechanical properties of concrete cannot be ruled out during extended operation beyond 40 years.

\section{Acknowledgments}

This manuscript has been authored by UT-Battelle, LLC, under contract DE-AC0500OR22725 with the US
Department of Energy. The United States Government retains and the publisher, by accepting the article for publication, acknowledges that the United States Government retains a nonexclusive, paid-up, irrevocable, worldwide license to publish or reproduce the published form of this manuscript, or allow others to do so, for United States Government purposes.

\section{References}

1. H. Hilsdorf, J. Kropp, H. Koch, The effects of nuclear radiation on the mechanical properties of concrete, Special Publication of the American Concrete Institute 55, 223-254 (1978)

2. O. Kontani, Y. Ichikawa. A. Ishizawa, M. Takizawa, O. Sato, Irradiation effects on concrete structure, International Symposium on the Ageing Management and Maintenance of Nuclear Power Plants, 173-182 (2010)

3. H. Graves, Y. Le Pape, D. Naus, J. Rashid, V. Saouma, A. Sheikh, and J. Wall,. Expanded Material Degradation Assessment (EMDA), Vol. 4: Aging of Concrete, NUREG/CR-7153, ORNL/TM-2011/545. U.S. NRC, (2014)

4. U.S. NRC, Agency-wide Documents Access and Management System (ADAMS), http://www.nrc.gov/reading-rm/adams.html (2015)

5. I. Remec, Status Report on Defining a Unified Parameter for Characterization of Radiation Intended for Evaluation of Radiation-induced Degradation of Concrete, Technical Report, ORNL, (2014)

6. T. Esselman, et al., Expected Condition of Concrete at Age 80 Years of Reactor Operation, Technical Report, A13276-R-001, Lucius Pitkin, Inc., (2013)

7. K.G. Field, I. Remec, Y. Le Pape, Radiation effects in concrete for nuclear power plants - Part I: Quantification of radiation exposure and radiation effects, Nuclear Engineering and Design, Vol. 282, pp. 126-143, ISSN 0029-5493 (2015)

8. I. Remec, et al., Characterization of Radiation Fields in Biological Shields of NPPs for Assessing Concrete Degradation, EPJ Web of Conferences 106, (2016)02002,http://dx.doi.org/10.1051/epjconf/2016 10602002

9. L.R. Greenwood, SPECOMP Calculations of Radiation Damage in Compounds, ASTM-STP l00l, pp. 598-602, (1989)

10. ASTM E722 Standard Practice for Characterizing Neutron Fluence Spectra in Terms of an Equivalent Monoenergetic Neutron Fluence for RadiationHardness Testing of Electronics, Annual Book of ASTM Standards, Vol. 12.02 (2015)

11. P. Beynel, et al., Compilation of Radiation Damage Test Data, Part III: Materials used around highenergy accelerators, CERN 82-10, (1982)

12. T.M. Rosseel, et al., Recent Advances in Understanding Radiation Damage In Reactor Cavity Concrete, Transactions, SMiRT-23, Manchester, United Kingdom - August 10-14, (2015) 